\title{
Investigation of the speed-up effects of wind flow over typical terrains covered by vegetation
}

\author{
Chao $\mathrm{Li}^{1, \mathrm{a}}$, J.H. Wang ${ }^{1}$ \\ ${ }^{1}$ Shenzhen Graduate School, Harbin Institute of Technology, Shenzhen 518055, China \\ alichaosz@hit.edu.cn
}

Keywords: speed-up; vegetation; typical terrain; wind tunnel; atmospheric boundary layer; Abstract. The wind characteristics of 6 typical hills $\left(15^{\circ}, 30^{\circ}, 45^{\circ}\right.$ escarpments and ridges) covered by grass and forest vegetation were investigated by wind tunnel test. The velocity ratio distribution on the crest and downwind slope were obtained, and the effects of slopes, hill shapes and ground roughness on the wind velocity ratios were summarized. Through comparison with Codes from several countries, 5 recommended revisions were proposed for the current Chinese loadings Codes.

\section{Introduction}

Study on the wind field over complex terrains has a wide range of practical application, such as: the wind resistance design of structures, evaluation of wind energy and micro-siting of wind turbines. For an extensive guidance, most of the researches focused on several typical models of complex terrain such as escarpments, symmetrical ridges and axisymmetric hills and measured the velocity field using pressure probe, hot-wire anemometer and Laser Doppler Anemometer in wind tunnels [1]. T. T. Ngo and C. W. Letchford [2] used carpet with thickness of $10 \mathrm{~mm}$ to simulate the rough terrain. However, there is limited data available that could demonstrate the relationship between these roughness models and real vegetation and their effects on the turbulent boundary layer flow over complex terrain.

\section{Experimental Setup}

The present study was conducted in the Wind Tunnel and Water Flume Laboratory of Harbin Institute of Technology, which is a closed return wind tunnel. Boundary layer winds were simulated using spires and roughness cubes in the small working section of $4 \mathrm{~m}$ wide, $3 \mathrm{~m}$ high and $25 \mathrm{~m}$ long. The free-stream flow is operated at a speed of $10 \mathrm{~m} / \mathrm{s}$.

The complex terrains in mountainous area are generally covered by vegetation. Two kinds of representative vegetation, grass and forest, are selected in the present study. As shown in Figure 1 a), the height of grass model is $1-2 \mathrm{~mm}$, which is filamentous powder of grass and glued to the surface of terrain model. As shown in Figure $1 \mathrm{~b}$-c), the height of tree model is about 19-21mm, the crown diameter is about $17-19 \mathrm{~mm}$, and the plant spacing is $20 \mathrm{~mm}$. These tree models are staggered arranged and stuck into the pre-drilled holes on the terrain models. Hills are usually covered by uniformly and continuously distributed vegetation. To equilibrate the roughness of hill surface and avoid the roughness change effect, the inflow boundary layer wind was generated by about $6 \mathrm{~m}$ long vegetation models in the upwind region. Consequently, only the topographic effects on the flow will be observed. The total number of tree models manufactured for this study is approximately 20,000.Six 2D escarpments, symmetrical ridges with slope of $15^{\circ}, 30^{\circ}$ and $45^{\circ}$ are chosen to study their topographic influences when covered by vegetation.

All the models are $200 \mathrm{~mm}$ in height and $1000 \mathrm{~mm}$ in crosswise direction. To maintain the 2D flow characteristics, two $1000 \mathrm{~mm}$ high, $7000 \mathrm{~mm}$ long and $10 \mathrm{~mm}$ thick sideboards are installed at both sides. The definition of hill models dimensions are illustrated in Figure 2. Coordinate $x$ equal 0 at the crest of ridges and escarpments. 


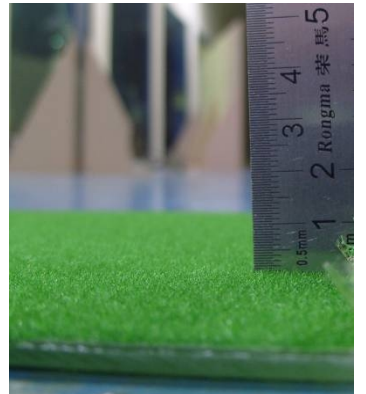

a) grass vegetation

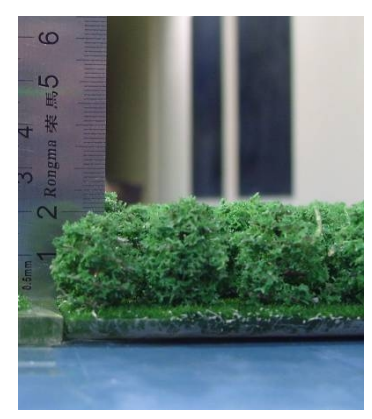

b) front view of forest vegetation c) top view of forest vegetation

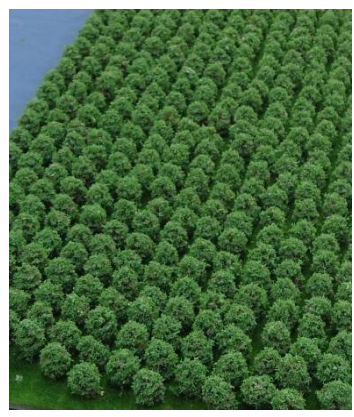

Figure 1 Two kinds of vegetation models

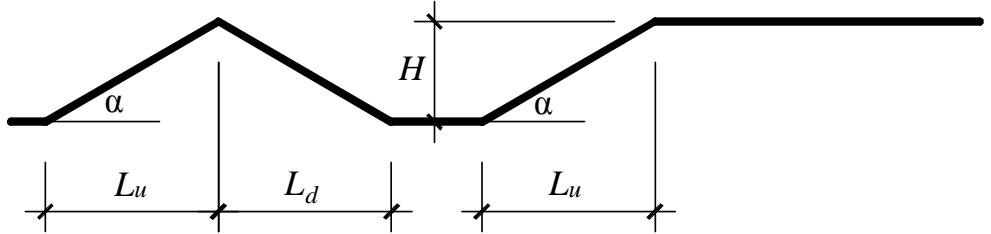

Figure 2 schematic diagram of typical hills dimensions

Measurements of flow turbulence were taken using 1D single-sensor (55P11) and 2D X-array dual-sensor (55P61) in conjunction with a 54N80/81 DANTEC constant temperature anemometer system. The X-array probe was used near the ground to measure Reynolds stress for determining the friction velocity. In virtue of a reference wind velocity probe (54T29), all the hot-wire probes are calibrated by a fourth order polynomial relation between voltages and velocities. The measurement errors are controlled less than $0.5 \%$. The output signals for each point were digitized at a sampling rate of $1 \mathrm{kHz}$ giving a total of 65,536samples. The height of the lowest measurement point was $10 \mathrm{~mm}$ from the model surface for grass vegetation, and $30 \mathrm{~mm}$ for forest vegetation. All the measured profiles are $2.5 \mathrm{H}$ from hill surface and include ten measuring points. Locations of measuring points are shown in Figure 3.

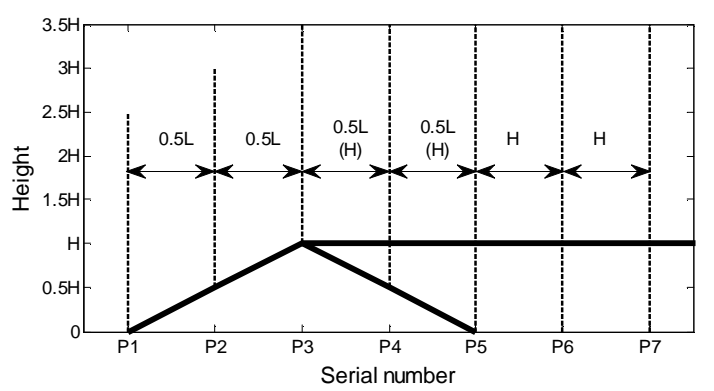

Figure 3 Locations of measuring points

\section{Aerodynamic Roughness of Vegetation Models and Characteristics of Inflow}

To make our results referable, the relationship between our vegetation models and vegetation in the real world should be established firstly. Herein is the aerodynamic roughness which is the bridge between them and need to be determined first.

The aerodynamic roughness characterize the weaken effects of earth surface acting on wind. The velocity at height $z$ described using logarithmic law is

$u_{z}=u_{*} / \kappa \ln \left[\left(z-z_{d}\right) / z_{0}\right]$,

where $z_{0}$ is the aerodynamic roughness length, $z_{d}$ is the zero plane displacement, $\kappa$ is the von Kármán constant, $u_{*}$ is the friction velocity

$u_{*}=\sqrt{\tau_{0} / \rho}$.

where $\tau_{0}$ is the wall shear stress, a drag force on unit area, $\rho$ is the air density. In the near wall region where $y^{+}>40$, Reynolds stress is approximately equal to wall shear stress, so the friction velocity could be measured using the equation below, 
$u_{*}=\sqrt{-\overline{u^{\prime} w^{\prime}}}$

where $u^{\prime}$ and $w^{\prime}$ is the fluctuating velocities in longitudinal and vertical directions respectively.

Table 1 The aerodynamics roughness of the vegetation models and undisturbed inflow characteristics

\begin{tabular}{ccccccc}
\hline Vegetation & Method & $z_{0}(\mathrm{~mm})$ & $z_{d}(\mathrm{~mm})$ & $u^{*}(\mathrm{~m} / \mathrm{s})$ & $\operatorname{Re}^{*}$ & $\alpha$ \\
\hline \multirow{2}{*}{ Grass } & Fitting & 0.0017 & 1.00 & 0.26 & 0.030 & 0.097 \\
& Mass conservation & 0.0011 & 0.82 & 0.25 & 0.019 & \\
Forest & Fitting & 0.90 & 18.0 & 0.49 & 30.1 & 0.21 \\
\hline
\end{tabular}

The three main approaches to determine the surface aerodynamic roughness is, the logarithmic profile fitting method, mass conservation method [3] and morphometry method. The first two methods are appropriate for our experiments and the results are listed in Table $1 . \operatorname{Re}^{*}=z_{0} u_{*} / v$ is the roughness Reynolds number and $\alpha$ is the exponent when fit in the power law. It is worth noting that mass conservation method requires a high-precision measurement of surface friction velocity, whereas the logarithmic profile fitting method totally depends on the measured velocity profile.

\section{Mean Wind Speed Ratio at Crest}

Wind Speed Ratio (WSR) could reflect the topographic effects on the boundary layer flow apart from the onset flow magnitude, which is defined as

$r_{\theta}(x, y, z)=\frac{U(x, y, z)}{U_{0}(z)}$

Comparison of WSR at crest for each inclination is shown in Figure 4. Obviously, $r_{\text {forest }}$ is larger than $r_{\text {grass }}$ for all the three slopes whether escarpment or ridges. For the Similar conclusions have also been found by Ngo and Letchford[2].

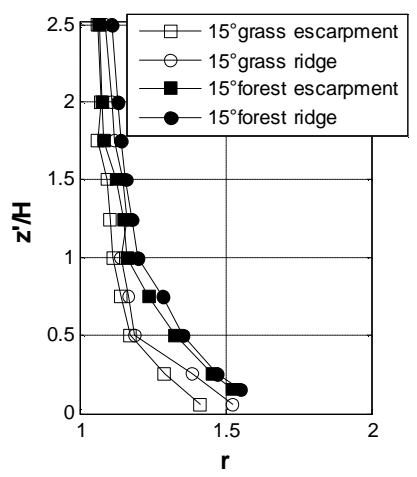

a) $15^{\circ}$

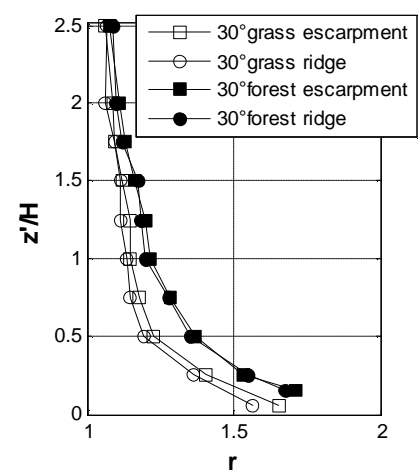

b) $30^{\circ}$

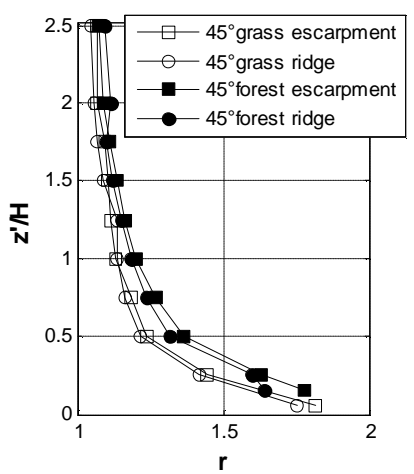

c) $45^{\circ}$

Figure 4 Comparison of WSR at crest for each inclination

The effects of hill shape and roughness on speed-up at crest could also be found in Figure 4. For a subdued slope say $15^{\circ}$, the velocity ratios of ridges is larger than escarpments. For steep slopes such as $30^{\circ}$ and $45^{\circ}$, the velocity ratios of ridges becomes smaller than escarpments. This interesting phenomenon could be explained by the different separation flow in the downwind of hills. For shallow slope ridges, the separation may amplify the speed-up motion. However, for steeper ridges, the speed-up is depressed. Contrarily, the separation at the crest of escarpment is relatively small.

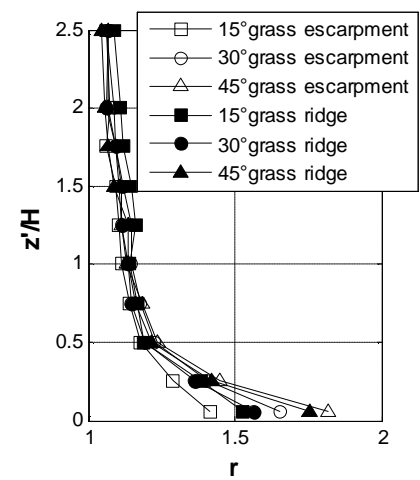

a) grass

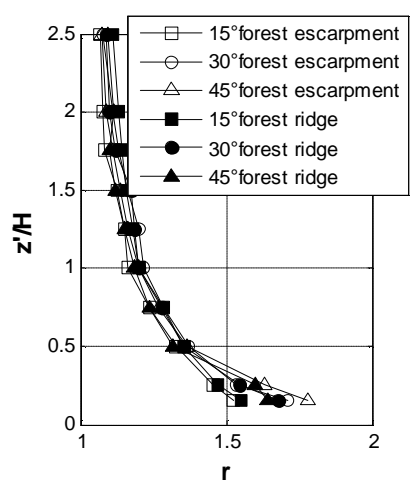

b) forest

Figure 5 Comparison of WSR at crest 
To present the effects of slope and hill types, WSR profiles at crest are compared for hills covered by grass and forest vegetation respectively in Figure 5. It can be perceived that velocity ratio $r$ at crest is growing all the time as the slope increases from $15^{\circ}$ to $45^{\circ}$. The comparison of wind speed ratio at crest for each inclination is shown in Figure 6. For grass ground, the code method is a conservative design method. However, it is danger for ground covered by forest.

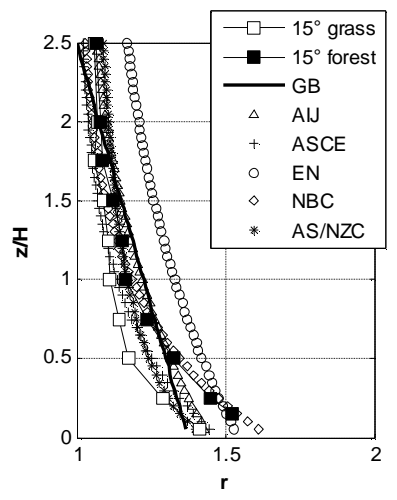

a) $15^{\circ}$

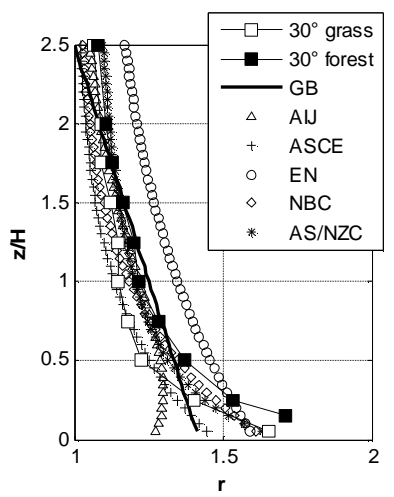

b) $30^{\circ}$

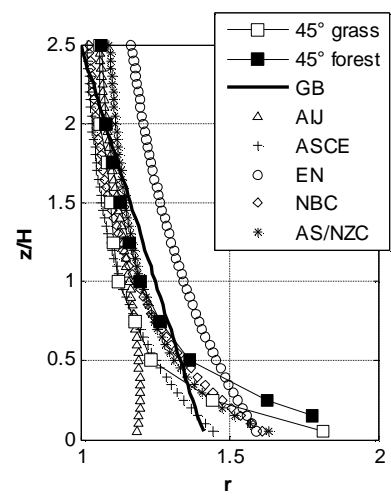

c) $45^{\circ}$

Figure 6 Comparison of wind speed ratio at crest for each inclination

\section{Conclusions}

The speed-up phenomena at the crest of 6 large scale typical hill models $\left(15^{\circ}, 30^{\circ}, 45^{\circ}\right.$ escarpments and ridges) covered with high fidelity grass and tree models were investigated in wind tunnel. The main findings are summarized below:

(1) Under the condition that the roughness of inflow is same as the hill surface, $r_{\text {forest }}>r_{\text {grass }}$. So, roughness is a indispensable factor that should be taken into account in the future wind loading code.

(2) For a subdued slope say $15^{\circ}, r_{\text {ridge }}>r_{\text {escarpment }}$, and for steep slopes such as $30^{\circ}$ and $45^{\circ}$, $r_{\text {escarpment }}>r_{\text {ridge }}$.

(3) Velocity ratio $r$ at crest is growing all the time as the slope increases from $15^{\circ}$ to $45^{\circ}$. We recommend increasing the present upper limit to at least $45^{\circ}$ or $60^{\circ}$ like AIJ 2004.

\section{Acknowledgements}

The work described in this paper was supported by grants from Shenzhen Science and Technology Innovation Committee (Project no. JCYJ20130329154442496), the National Natural Science Foundation of China (Project no. 51308167) and HIT NSRIF 2015086, which are all gratefully acknowledged.

\section{References}

[1]. Ishihara, T., K. Hibi and S. Oikawa, A wind tunnel study of turbulent flow over a three-dimensional steep hill. Journal of Wind Engineering and Industrial Aerodynamics, 1999. 83(1-3): p. 95-107.

[2]. Ngo, T.T. and C.W. Letchford, Experimental study of topographic effects on gust wind speed. Journal of Wind Engineering and Industrial Aerodynamics, 2009. 97(9-10): p. 426-438.

[3]. Bruin, H.A.R. and C.J. Moore, Zero-plane displacement and roughness length for tall vegetation, derived from a simple mass conservation hypothesis. Boundary-Layer Meteorology, 1985. 31(1): p. 39-49. 